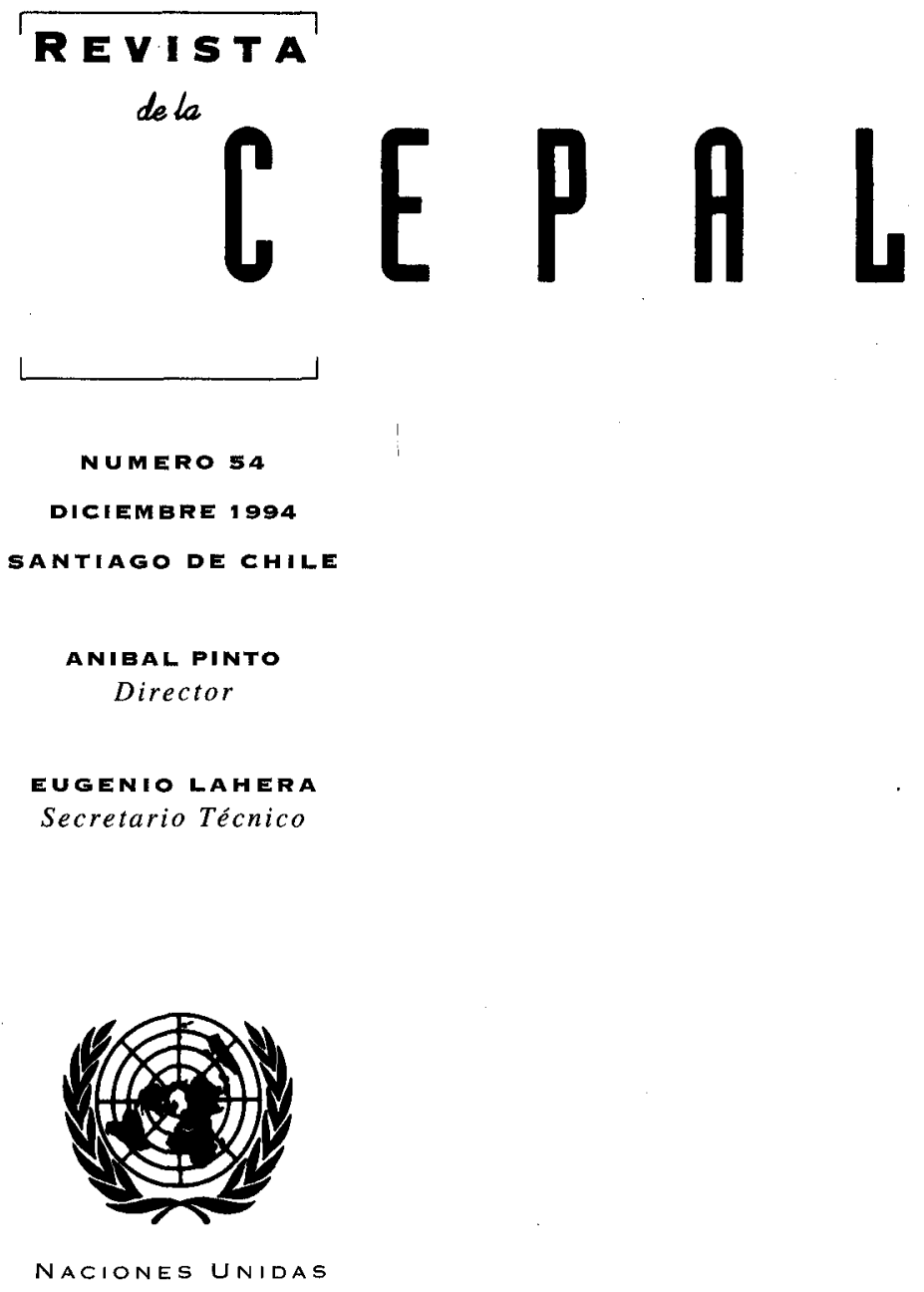


Mercados de salud: morfología, comportamiento y regulación

Jorge Katz y Ernesto Miranda

¿Liberalización o desarrollo financiero?

Günther Held

Ajuste fiscal y gasto social

Rossella Cominetti

Logros y obstáculos en la educación formal de las mujeres

Diane Alméras

¿Qué se entiende por flexibilidad del mercado de trabajo?

Ricardo A. Lagos

Modernización de la supervisión bancaria

Christian Larraín

Costos y beneficios de la integración centroamericana

Luis Cáceres

Algunas enseñanzas de las privatizaciones en Argentina

Daniel Azpiazu y Adolfo Vispo

Ventajas comparativas extraordinarias y crecimiento a largo plazo:

el caso de Ecuador

André A. Hofman y Rudolf Buitelaar

Industria cultural y nuevos códigos de modernidad

Martín Hopenhayn

Orientaciones para los colaboradores de la Revista de la CEPAL

Publicaciones recientes de la CEPAL 


\section{Mercados de salud: morfología, comportamiento y regulación}

\section{Jorge M. Katz Ernesto Miranda R.}

División de Desarrollo Productivo y Empresarial de Ia CEPAL.

Facultad de Economía de la Universidad de Chile
Este artículo analiza los mercados de bienes y servicios vinculados a la atención de la salud, centrándose en tres de ellos: el de servicios médicos, el de servicios de internación hospitalaria públicos y privados y el de productos farmacéuticos, que son los que absorben entre el $70 \%$ y $80 \%$ del total de los gastos operacionales de salud. Estos mercados exhiben estructuras de competencia imperfecta, fuertes externalidades en el consumo de atenciones de salud y una estrecha interdependencia. Las dos primeras características hacen que si se dejan librados a sus propias fuerzas su funcionamiento no conduce a soluciones óptimas en cuanto a la asignación de los recursos y a la maximización del bienestar. A su vez, la interdependencia se traduce en que las distorsiones presentes en cualesquiera de ellos se transmiten y contribuyen a magnificar —en la mayoría de los casos- aquéllas presentes en los otros. Lo expuesto tiene efectos cruciales en el diseño de la política pública, la que naturalmente deberá enmarcarse también en las peculiaridades económicas, sociales y políticas de cada país. Aquí se analizan algunas medidas de regulación que parecen aconsejables en cada uno de estos mercados, las que apoyadas por la reingeniería institucional, legal y normativa que cada caso nacional haga aconsejable, permitirían si no eliminar al menos moderar las incompatibilidades con las ideas desregulatorias y de libre juego del mercado que hoy día parecen adecuadas en otros campos de la vida económica. 
I

\section{Introducción}

El cuidado, mantención y recuperación de la salud de los miembros de una determinada sociedad se realiza mediante el empleo de recursos humanos (médicos, otros profesionales de la salud y otro personal), equipos e instrumental, servicios de hospitalización públicos y privados, vacunas y fármacos, e insumos sanitarios y generales. Estos recursos son combinados en proporciones variables, las que normalmente son decididas por los profesionales médicos: en la mayoría de los casos son ellos quienes definen los exámenes necesarios, asumen la responsabilidad por el diagnóstico clínico de las patologías identificadas y determinan las terapias. ${ }^{1}$

Cada uno de los servicios e insumos mencionados identifica un mercado particular en el que operan distintos proveedores — públicos y privados; nacionales y extranjeros- y usuarios, ya sea de bienes y servicios finales o de bienes y servicios intermedios, de consumo o de inversión. En dichos mercados prevalece un precio (o más bien, un espectro de precios) alcanzado en virtud de ciertas reglas conductuales de los agentes - proveedores y usuarios o "pacientes"que se desenvuelven enmarcados por estructuras de mercado más o menos competitivas.

Se trata, por lo general, de mercados imperfectos en los que la oferta tiene relativa capacidad para crear su propia demanda. ${ }^{2}$ La varianza de los precios de

\footnotetext{
$\square$ Este artículo contiene parte del material preparado por los autores para el estudio CEPAL/OPS titulado Salud, equidad y transformación productiva en América Latina y el Caribe, que con la signatura LC/G.1813 (SES. 25/18) fue presentado en el $25^{\circ}$ periodo de sesiones de la CEPAL (Cartagena de Indias, abril de 1994). Las opiniones aquí vertidas son de índole personal y en nada comprometen a los organismos mencionados. Las ideas contenidas en el artículo fueron discutidas en diversas oportunidades con R. Franco, J. Ramos, F. León, y M. Boyer, a quienes se agradece sus múltiples contribuciones y se exime de toda responsabilidad por lo aquí expuesto.

1 En un estudio realizado hacia fines de los años setenta, Blumberg estima que cerca del $70 \%$ del gasto en servicios de salud que efectúa una comunidad depende de decisiones tomadas por profesionales médicos.

2 La interdependencia de la oferta y la demanda derivada de la capacidad que aquélla tiene para modelar a esta última, constituye un rasgo central de los mercados de salud. Esto afecta el comportamiento de los proveedores de bienes y servicios y, como contrapartida, la naturaleza y funcionamiento del aparato regulatorio que es necesario establecer a fin de inducir conductas microecónomicas conducentes al óptimo social. La parte final de este artículo aborda con mayor detalle los temas de política pública vinculados con la regulación en el campo de la salud.
}

bienes y servicios que son sustitutos idénticos o similares suele ser significativa, ya que la noción de calidad y valor terapéutico es difusa incluso para los propios proveedores. En virtud del fenómeno conocido como asimetría de información, el consumidor no logra una percepción precisa de cuáles son los medios que permiten satisfacer sus necesidades ni de cuánto mejor es una opción de gasto frente a otra, por lo que la soberanía del consumidor sólo puede materializarse muy imperfectamente. Lo aleatorio de las morbilidades, la variabilidad de los diagnósticos y terapias, y la incertidumbre respecto del desarrollo tecnológico en salud y su costo, interfieren con frecuencia en el manejo del riesgo, dando origen tanto a fenómenos de selección de riesgo como a los de selección adversa.

Tres de dichos mercados - el de servicios médicos, el de servicios de hospitalización y el de productos farmacéuticos- absorben entre 70 y $80 \%$ del total de los recursos que una determinada sociedad gasta en el cuidado y recuperación de la salud de sus miembros. ${ }^{3}$ Cada uno de estos mercados nos enfrenta con una problemática específica de organización y comportamiento que examinaremos individualmente primero, para pasar luego al estudio de su interdependencia.

$\mathrm{El}$ análisis del modelo de organización de los servicios de salud en una determinada sociedad debe hacerse prestando atención a dicha interdependencia, debido al impacto que ella tiene sobre la distribución de los recursos entre los distintos proveedores de bienes y servicios que interactúan en este campo. Argumentaremos en lo que sigue que el funcionamiento del sistema de salud está fuertemente condicionado por los cambios que dicha distribucion va sufriendo a través del tiempo.

En la medida en que cada uno de los núcleos prestadores de servicios puede hacer ajustes de cantidad o calidad cuando se produce una reducción de los precios relativos de los servicios o bienes que ofrecen, el comportamiento de cada uno de los mercados y la interdependencia entre ellos adquieren un papel crucial para comprender la evolución del sistema en su con-

\footnotetext{
3 A título de ejemplo, observamos que en Estados Unidos los servicios médicos absorben $20 \%$ del total de los gastos en salud, los costos de internación hospitalaria $40 \%$ y el pago por medicamentos cerca del 10\% del gasto total (Feldstein, 1983, p. 33). En Argentina, en cambio, los primeros absorben $28 \%$, los segundos $22 \%$ y los terceros $30 \%$ del gasto total (Katz, y Muñoz, 1988).
} 
junto y sus rasgos centrales en términos de eficacia y eficiencia microeconómicas y equidad distributiva.

La sección II está dedicada al análisis de los rasgos morfológicos y la interdependencia de los mercados de salud; la sección III explora brevemente las connotaciones para la política pública del diagnóstico de organización sectorial que se hace aquí, y la sección IV presenta nuestras reflexiones finales.

\section{II}

\section{Morfología e interdependencia de los mercados de salud}

El dinamismo de los mercados de salud está determinado principalmente por el mercado de los servicios médicos, puesto que los profesionales médicos son el factor crucial del proceso de producción de servicios de salud. Las prácticas médicas determinan las tecnologías empleadas, y de ellas dependen por tanto las proporciones en que se utilizan los otros factores productivos. En un amplio rango, las demandas en los

CUADRO 1

América Latina y el Caribe (29 países): Recursos humanos para la atención de la salud, airededor de 1990

\begin{tabular}{|c|c|c|c|c|c|}
\hline Países & Población (miles) & Médicos & Odontólogos & $\begin{array}{c}\text { Enfermeras } \\
\text { profesionales }\end{array}$ & $\begin{array}{l}\text { Auxiliares de } \\
\text { enfermería y } \\
\text { otro personal }\end{array}$ \\
\hline
\end{tabular}

\begin{tabular}{|c|c|c|c|c|c|}
\hline Argentina & 32700 & 88800 & 21900 & 18000 & 26000 \\
\hline Bahamas & 259 & 373 & 58 & 682 & 1000 \\
\hline Barbados & 258 & 294 & 33 & 836 & 502 \\
\hline Bermuda & 61 & 71 & 27 & 27 & 523 \\
\hline Bolivia & 7300 & 3392 & 333 & 1869 & 4713 \\
\hline Brasil & 151400 & 208966 & 118609 & 57047 & 205110 \\
\hline Colombia & 32800 & 36551 & 19498 & 15251 & 31125 \\
\hline Costa Rica & 3100 & 4027 & 1200 & 3021 & 4000 \\
\hline Cuba & 10740 & 46860 & 8057 & 5474 & 68469 \\
\hline Chile & 13400 & 15015 & 7000 & 5653 & 28794 \\
\hline Dominica & 72 & 38 & 6 & 233 & $\ldots$ \\
\hline Ecuador & 10800 & 15737 & 4847 & 5045 & 11384 \\
\hline El Salvador & 5300 & 4525 & 1182 & 2655 & 2439 \\
\hline Guatemala & 9500 & 7601 & 251 & 3120 & 11281 \\
\hline Guyana & 800 & 138 & 11 & 708 & 83 \\
\hline Haití & 6600 & 564 & 81 & 728 & 1761 \\
\hline Honduras & 5300 & 3803 & 622 & 1352 & 4936 \\
\hline Islas Vírgenes & 99 & 21 & 1 & 48 & 27 \\
\hline Jamaica & 2400 & 338 & 54 & 2130 & 1355 \\
\hline México & 83300 & 149432 & $\ldots$ & 80760 & 61540 \\
\hline Montserrat & 14.4 & 5 & 1 & 38 & 18 \\
\hline Nicaragua & 3800 & 1723 & 183 & 2200 & 2569 \\
\hline Panamá & 2500 & 4131 & 957 & 2630 & 3341 \\
\hline Paraguay & 4400 & 2924 & 1160 & 1375 & 3183 \\
\hline Perú & 21900 & 23771 & 6259 & 19612 & 38850 \\
\hline Rep. Dominicana & 7200 & 11130 & 1898 & 1360 & 4675 \\
\hline Trinidad y Tabago & 1300 & 911 & 109 & 2037 & 1438 \\
\hline Uruguay & 3100 & 11530 & 3512 & 1710 & 1500 \\
\hline Venezuela & 19800 & 32616 & 7945 & 15026 & 40324 \\
\hline
\end{tabular}

Fuente: Para las cifras de población, Banco Mundial, Informe sobre el desarrollo mundial 1993, Washington, D.C., 1993. Para las demás cifras, Organización Panamericana de la Salud (OPS)/Organización Mundial de la Salud (OMS), Las condiciones de salud en las Américas 1994. (en prensa). 
CUADRO 2

América Latina y el Caribe (29 países): Relación entre población y recursos humanos para la atención de la salud, alrededor de 1990

\begin{tabular}{|c|c|c|c|c|}
\hline Países & $\begin{array}{l}\mathrm{N}^{\circ} \text { de habitantes } \\
\text { por médico }\end{array}$ & $\begin{array}{c}\mathrm{N}^{\circ} \text { de habitantes } \\
\text { por odontólogo }\end{array}$ & $\begin{array}{l}\mathrm{N}^{\circ} \text { de habitantes } \\
\text { por enfermera }\end{array}$ & $\begin{array}{c}\mathrm{N}^{\circ} \text { de habitantes por } \\
\text { miembro del restante } \\
\text { personal de salud }\end{array}$ \\
\hline
\end{tabular}

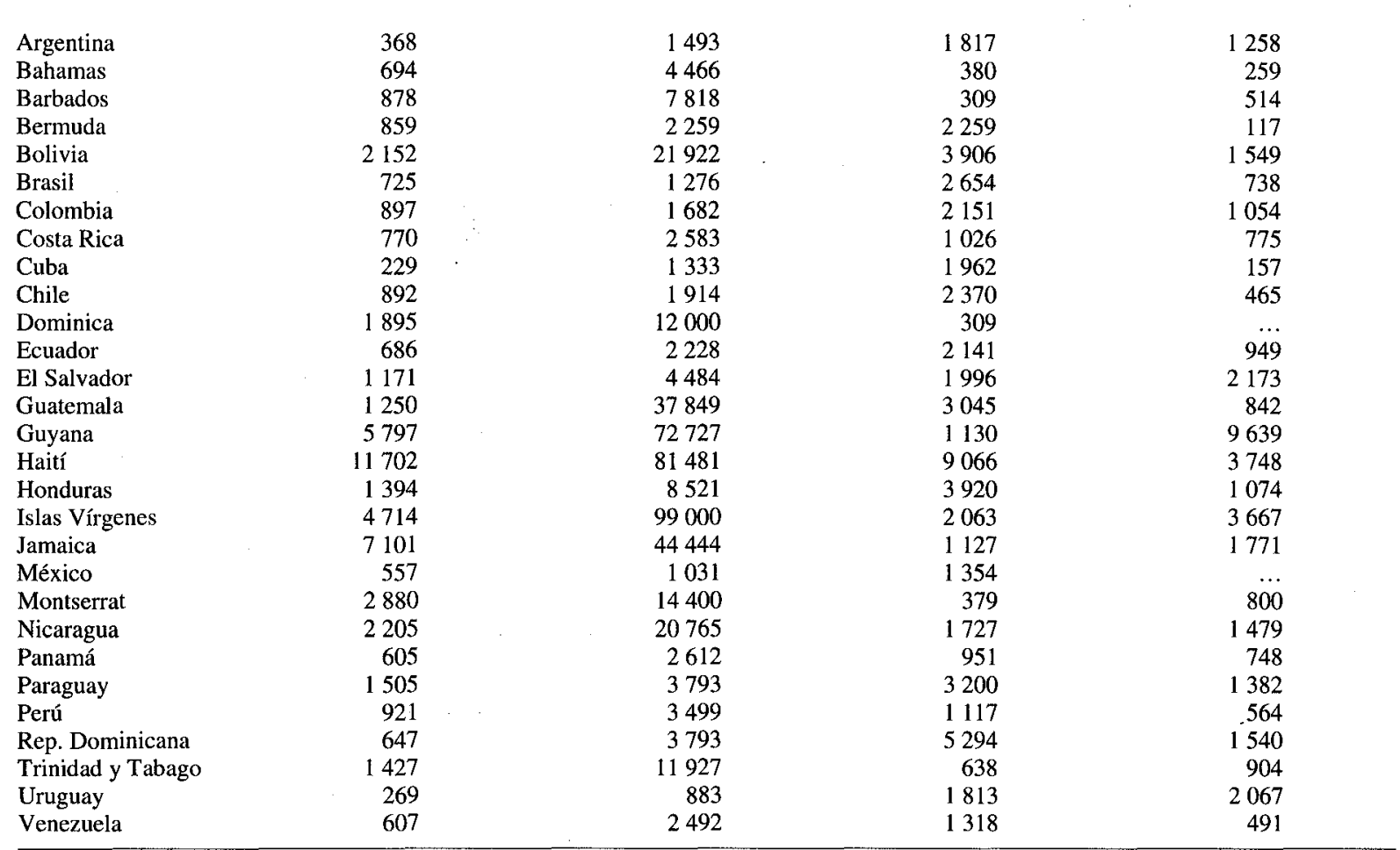

Fuente: Para las cifras de población, Banco Mundial, Informe sobre el desarrollo mundial 1993, Washington, D.C., 1993. Para las demás cifras, Organización Panamericana de la Salud (OPS)/Organización Mundial de la Salud (OMS), Las condiciones de salud en las Américas 1994 (en prensa).

mercados de instrumental y equipamiento, insumos, fármacos y servicios de hospitalización, son demandas derivadas. Aunque entre estos factores hay posibilidades de complementación y sustitución productiva, de todos modos las proporciones en que ellos se emplean están determinadas por los médicos, y en menor grado, por el resto de los profesionales de la salud.

\section{El mercado de servicios médicos}

La oferta de servicios médicos varía notablemente entre países latinoamericanos, así como también entre regiones al interior de cada uno de ellos (cuadro 1). Esto se refleja, por un lado, en las diferencias que muestra el

4 El índice promedio del conjunto de países de la Organización de Cooperación y Desarrollo Económicos (OCDE) es de 2,3 médicos por cada 1000 habitantes (Schieber y otros, 1991). Vemos así que índice de habitantes por médico (cuadro 2): en algunos países es similar al promedio europeo, en tanto que en otros solamente alcanza a una fracción de aquél. Así, en tanto que Argentina, Uruguay y Cuba muestran en promedio, un índice de cerca de un médico por cada 300 habitantes, en Chile, Colombia y Perú este es de uno por cada 900 , y en varios otros países sólo de uno por más

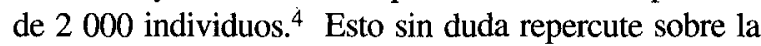

en países como Argentina, Uruguay o Cuba la saturación del mercado de servicios médicos es hoy bastante mayor que la del promedio de los países industrializados, con una fuerte concentración de dichos profesionales en los núcleos urbanos y las grandes metrópolis. Montevideo, por ejemplo, tiene un médico cada 200 personas, y la ciudad de La Plata (capital de la Provincia de Buenos Aires, Argentina) exhibe la inusual tasa de un profesional cada 120 personas, lo cual es prácticamente inédito a escala mundial. Respecto de los índices europeos, véanse Schieber y Poullier (1989) y Greenwald (1991). 
tasa de consultas médicas por habitante, indicador que también registra fuertes diferencias entre países $\mathrm{y}$, al interior de ellos, entre sus regiones.

Por otro lado, además de la densidad absoluta de habitantes por médico, en el comportamiento del mercado de servicios médicos influyen también tres grandes conjuntos de variables. El primero se refiere al ritmo de crecimiento, grados de especialización y composición por género de la oferta de nuevos graduados —en medicina, odontología, enfermería y otras profesiones de la salud- y a su localización geográfica. Dichas variables afectan tanto la forma como el desplazamiento en el tiempo de la curva de oferta de servicios, incidiendo por lo tanto sobre el precio - los aranceles de los servicios médicos_-, la calidad y la forma de organización del acto médico-asistencial. Influyen en esto, entre otros factores, las condiciones de acceso a la formación universitaria: el examen de ingreso $\mathrm{u}$ otras formas de selección que limitan la matrícula estudiantil; los requisitos de acreditación para el ejercicio profesional previstos en el marco institucional y regulatorio prevalente en cada sociedad; los mecanismos de especialización existentes en la profesión médica y en las otras profesiones de la salud, y la magnitud relativa de las graduaciones femeninas, en la medida en que las médicas jóvenes exhiben una propensión mayor a actuar en jornada parcial y en relación de dependencia que los profesionales varones.

Respecto del sistema educativo, es preciso tomar en cuenta sus características cuantitativas - condiciones de ingreso a la carrera de medicina, alumnos matriculados, tiempo y costo de la formación, naturaleza de las residencias médicas, tasas de especialización, índices de deserción, etc.-, y aquéllas cualitativas, relacionadas con el mayor o menor contenido "biologista" o "social" de la formación profesional. Sobre el sistema educativo de pregrado, Belmartino y otros (1990), han dicho que: "La situación actual puede caracterizarse de la siguiente manera: a.- Se otorga importancia particular al tipo de práctica que se realiza en las instituciones hospitalarias dedicadas a la atención de enfermedades agudas con baja prevalencia; b.- Se pone el énfasis en la función asistencial dirigida sobre las fases más activas de la enfermedad, relegando a segundo plano aspectos tales como rehabilitación, reinserción, seguimiento de crónicos, etc.; c.- Se privilegia la función curativa ignorando la importancia de la promoción y prevención; d.- No se tienen en cuenta los factores psicológicos, sociales y ambientales de la salud/enfermedad, ni se integran eficazmente al curri- culum los aportes de las ciencias sociales, las ciencias humanas y la epidemiología; e.- Se acentúan los aspectos memorísticos del aprendizaje, descuidando la capacidad de raciocinio y el desarrollo del criterio clínico para la evaluación de la condición del paciente". Y han concluido que "el sistema formador proporciona las bases intelectuales de la reproducción del modelo médico hegemónico".

En otros términos, en el marco de una medicina volcada hacia la alta complejidad, la "sobremedicalización" y la atención reparatoria ex post, la formación de los médicos -dado que se debe preparar profesionales capaces de integrarse eficientemente al sistema - termina por acentuar dichos rasgos, forzando a los nuevos graduados a una rápida especialización, al uso de tecnologías de alta complejidad y a una fragmentación cada vez mayor del acto médico.

$\mathrm{El}$ segundo conjunto de variables que incide en el comportamiento del mercado de servicios médicos es la organización sectorial - de naturaleza estrictamente pública o privada- que adopta cada sociedad para el financiamiento, la gestión y la provisión de estos servicios. Así, en un modelo de prestación y financiamiento públicos el médico actúa como funcionario del Estado y percibe un salario, en tanto que en un modelo mixto -en el que se combinan financiamiento y provisión del sector público, de las instituciones de la seguridad social (ISS) y del sector privado - surgen diversos comportamientos de mercado y formas de transferencia que en el primer caso son prácticamente irrelevantes.

En los modelos mixtos, los ingresos de la profesión médica $\rightarrow$ y de las otras profesiones de la salud, aunque en menor medida - no provienen sola y exclusivamente de salarios por tareas efectuadas en relación de dependencia en el ámbito publico. En este caso pasan a ser cada vez más significativos los honorarios profesionales percibidos en la práctica privada y la rentabilidad de la propiedad del instrumental y equipamiento y de la infraestructura de hospitalización . Con estos bienes de capital, los profesionales médicos operan como subcontratistas de las ISS, de las empresas privadas de prestación de servicios de salud, y en ocasiones, de las entidades públicas.

La evolución de la combinación público-privada hacia una creciente participación del sector privado guarda una estrecha relación con el desarrollo y formalización de los mercados de salud. A medida que éstos se desarrollan, las rentas provenientes de la propiedad de los bienes de capital e infraestructura pasan a representar una proporción cada vez mayor del total 
de los ingresos de los profesionales de la salud. A su vez, estas rentas de la propiedad son una función creciente de rentas asociadas a la introducción de equipos electromédicos de alta complejidad (tomógrafos, ecógrafos, cámaras gamma, etc.).

En estas situaciones, los esfuerzos por capturar y acrecentar la demanda de servicios de salud se alejan de la competencia mediante precios y reducciones de los costos de producción, para centrarse en cambio en la diferenciación de productos mediante una creciente sofisticación tecnológica. Esta conducta impulsa a los profesionales a acrecentar sus grados de especialización - esto es, invirtiendo en capital humano-, a adquirir instrumental y equipamiento, y a emplear métodos de diagnóstico y procesos terapéuticos con la tecnología más avanzada. Así, sus ingresos globales derivan cada vez más de la inversión y la innovación tecnológica. Asociado a lo anterior, aumentan y cambian sus características tanto las demandas sobre el sistema de formación de profesionales de la salud -lo que se combina con restricciones cada vez mayores para la entrada al mercado mediante requisitos de especialización- como las demandas sobre los productores de instrumental, equipamiento e infraestructura. El sector de mayor dinamismo pasa a ser entonces aquél en que se concentra la tecnología de vanguardia, cuya rentabilidad es mayor que en las áreas tradicionales.

Por último, el tercer conjunto de variables que influyen en el funcionamiento del mercado de servicios médicos se vincula a las formas de pago que prevalecen al interior de cada modelo organizacional: por salario, por acción de salud, por capitación, por tratamiento, por resultados, etc. En la práctica, se ha podido observar que el pago por acción de salud en el marco de un modelo mixto público/privado induce a la sobreprestación y a la expansión de los costos. También parece claro que al coexistir un aparato de prestaciones privado con otro de naturaleza pública, el rezago relativo de los salarios médicos en este último induce a la migración de profesionales hacia el sector privado, produciéndose así incentivos para la expansión de $\operatorname{costos}^{5}$ (OMS, 1993; Miranda, 1993b). La información disponible también indica que los pagos por "contrato capitado", "nomencladores globalizados" o "grupos de diagnóstico" — a diferencia de los pagos por acción de salud- trasladan el riesgo de la expansión de costos desde las entidades de financiamiento hacia las de provisión de servicios, for-

5 Estudios recientes del caso chileno ponen de relieve situaciones de este tipo. Véase por ejemplo Oyarzo, (1992 y 1993). zando a estas últimas a un manejo más cuidadoso de los recursos. Se generan así incentivos para controlar la sobreprestación y sobrefacturación mediante el establecimiento de normas técnicas para las tareas médico-asistenciales, y el empleo de sistemas de auditoría y otros de control ex post de resultados.

Los temas de la calidad y organización del acto médico también parecen estar asociados a los tres conjuntos de variables examinadas precedentemente. Sin un adecuado esfuerzo por establecer tales normas para las prestaciones y por fiscalizar ex post los resultados, los "contratos capitados", por ejemplo, implantados sólo como mecanismos de contención de costos, corren el riesgo de inducir a la subprestación y al deterioro de la calidad del acto médico. ${ }^{6}$

Basados en esta explicación, cada vez que en un modelo estrictamente público de financiamiento y prestación de servicios de salud se agudicen las restricciones presupuestarias, se deterioren los salarios y aumenten los tiempos de espera, cabe esperar que surjan mercados informales al interior de las entidades proveedoras públicas. En éstos, ciertos miembros de la comunidad - ya sea gracias a su mayor capacidad económica o compelidos por la urgencia de su necesidad- lograrían formas preferenciales de atención a cambio de pagos en especie, o retribuciones fuera del circuito oficial. ${ }^{7}$

Los problemas de comportamiento microecónomico son de naturaleza diferente cuando pensamos en modelos mixtos de organización sectorial, más abiertos y pluralistas que los estrictamente públicos. En los modelos mixtos cabe esperar dentro de la comunidad médica conductas que afecten, entre otros aspectos, el costo de los servicios, el ritmo de introducción de nuevas tecnologías y la organización del acto médico asistencial y su calidad, en un grado quizás mayor y más difícil de regular que en el modelo estrictamente público.

Estos tres conjuntos de variables —el ritmo de expansión de la oferta de nuevos graduados y su composición según el género, la localización, el grado de especialización, etc.; la naturaleza del modelo organizacional del sector salud, y los mecanismos de pago por los servicios - afectarán la participacion relativa

\footnotetext{
6 Esto podría ocurrir, por ejemplo, por la disminución de los minutos de consulta dedicados al paciente o del número de controles de salud posquirúrgicos.

7 Ejemplos de surgimiento de mercados informales de este tipo han sido identificados en estudios sobre el sector salud de los países antes socialistas y, en fecha más reciente, de países como Cuba y Costa Rica, entre muchos otros.
} 
de la comunidad médica en el total de los recursos que la sociedad gasta en salud. Asimismo, favorecerán —u obstaculizarán - conductas reactivas por parte de dicha comunidad.

En resumen, las variables y comportamientos analizados interactúan para determinar la participación de los profesionales de la salud en el ingreso. Dichos comportamientos van a reflejar rasgos idiosincráticos de cada sociedad, siendo necesario examinar cada caso en particular a la hora de diseñar y llevar a cabo los programas de política pública en esta materia. Así, cada país deberá enfrentar esta compleja problemática a fin de proponer un marco institucional y regulatorio que compatibilice los legítimos derechos econó- micos de los profesionales médicos y de los otros profesionales de la salud, con los intereses generales de la sociedad. La eficacia y eficiencia microeconómicas y la equidad de los sistemas de salud dependen ampliamente de ello.

\section{El mercado de servicios hospitalarios públi- cos y privados}

La oferta de servicios de hospitalización públicos y privados también exhibe enormes disparidades entre los países de la región (cuadro 3). Vemos así que en Argentina, Barbados, Cuba o Uruguay la dotación de camas por cada mil habitantes oscila en torno a 6 , en

CUADRO 3

América Latina y el Caribe: Camas de hospital por cada mil habitantes, 1964-1991

\begin{tabular}{|c|c|c|c|c|c|c|}
\hline América Latina & 1964 & 1967 & 1974 & 1978 & 1984 & 1991 \\
\hline \multicolumn{7}{|l|}{ Area Andina } \\
\hline Bolivia $(1991)^{\mathrm{a}}$ & 2.1 & 2.2 & 1.8 & 1.8 & 1.8 & 1.3 \\
\hline Colombia (1989) & 2.7 & 2.4 & 1.9 & 1.7 & 1.8 & 1.4 \\
\hline Ecuador (1991) & 1.9 & 2.4 & 2.1 & 2 & 1.9 & 1.6 \\
\hline Perú $(1992)^{b}$ & 2.5 & 2.4 & 2 & 2.9 & 1.7 & 1.5 \\
\hline Venezuela $(1992)^{c}$ & 3.3 & 3.2 & 2.9 & 2.7 & 2.7 & 2.6 \\
\hline \multicolumn{7}{|l|}{ Cono Sur } \\
\hline Chile $(1991)^{\mathrm{e}}$ & 4.3 & $\begin{array}{l}0.3 \\
4.4\end{array}$ & $\begin{array}{l}5.4 \\
3.6\end{array}$ & $\begin{array}{l}3.4 \\
3.6\end{array}$ & 2.9 & $\begin{array}{l}4.4 \\
3.2\end{array}$ \\
\hline Paraguay $(1991)^{f}$ & 2.2 & 2 & 1.5 & 1.5 & 1.4 & 1.2 \\
\hline Uruguay $(1991)^{\mathrm{g}}$ & 6.4 & 6.4 & 5.7 & 5.2 & 5 & 4.4 \\
\hline Brasil h $^{\text {h }}$ & 3.4 & 3.8 & 3.8 & 3.8 & 3.6 & 3.5 \\
\hline \multicolumn{7}{|l|}{ Istmo Centroamericano } \\
\hline Belice $(1989)^{\mathrm{i}}$ & 4.9 & 4.9 & 4.6 & 3.2 & 2.5 & 2.2 \\
\hline Costa Rica (1991) & 4.5 & 3.8 & 3.8 & 3.1 & 2.9 & 2.2 \\
\hline El Salvador (1992)j & 2.3 & 2.2 & 1.8 & 1.8 & 1.3 & 1.6 \\
\hline Guatemala $(1989)^{\mathrm{k}}$ & 2.6 & 2.5 & 2 & 1.6 & 1.6 & 1.6 \\
\hline Honduras (1992) & 2 & 1.7 & 1.7 & 1.3 & 9 & 1.1 \\
\hline Nicaragua (1991) & 2.3 & 2.3 & 2.2 & 1.6 & 1.6 & 1.2 \\
\hline Panamá (1991) & 3.2 & 3.3 & 3.2 & 3.9 & 3.6 & 2.7 \\
\hline México $(1991)^{1}$ & 2.2 & 2 & 1.2 & 0.9 & 0.8 & 0.8 \\
\hline \multicolumn{7}{|l|}{ Caribe Latino } \\
\hline Cuba (1991) & 5.5 & 4.8 & 4.2 & 4 & 6.1 & 6 \\
\hline Haití (1992) & 0.7 & 0.7 & 0.7 & 0.8 & 1 & 0.8 \\
\hline República Dominicana $(1992)^{\mathrm{m}}$ & 2.7 & 2.8 & 2.8 & 2 & 1.2 & 1.9 \\
\hline \multicolumn{7}{|l|}{ Resto del Caribe } \\
\hline Anguila (1991) & $\ldots$ & $\ldots$ & & & & 2.7 \\
\hline Antigua y Barbuda & 7.2 & 7 & 5.8 & 6.3 & 5.8 & $\ldots$ \\
\hline Antillas Holandesas y Aruba $(1992)^{n}$ & $\ldots$ & $\ldots$ & $\ldots$ & & & 7.6 \\
\hline Bahamas $(1991)^{\circ}$ & 5.5 & 4.9 & 3.9 & 4.3 & 4.1 & 4 \\
\hline Barbados $(1990)^{\mathrm{p}}$ & 5.8 & 10.4 & 8.7 & 8.7 & 8 & 8.1 \\
\hline Dominica $(1992)^{\mathrm{q}}$ & 4.9 & 4.5 & 4.3 & 3 & 3 & 3.3 \\
\hline Granada $(1991)^{\mathrm{r}}$ & 6.9 & 6.9 & 7.5 & 8.6 & 9 & 6.6 \\
\hline Guadalupe & $\ldots$ & $\ldots$ & $\ldots$ & $\ldots$ & $\therefore$ & $\ldots$ \\
\hline Guayana Francesa & $\ldots$ & $\ldots$ & $\ldots$ & $\ldots$ & & $\ldots$ \\
\hline Guyanas $^{\mathrm{s}}$ & 5.4 & 4.6 & 4.3 & 4.5 & 1.5 & $\ldots$ \\
\hline Islas Caimán (1991) & $\ldots$ & $\cdots$ & $\ldots$ & $\ldots$ & $\ldots$ & 2.6 \\
\hline Islas Turcos y Caicos (1992) & $\ldots$ & $\ldots$ & $\ldots$ & $\ldots$ & $\ldots$ & 2.9 \\
\hline Islas Vírgenes（EE.UU.) & $\ldots$ & & & $\ldots$ & & \\
\hline Islas Vírgenes (RU) $(1991)^{t}$ & 4.3 & 4.3 & 3.6 & 3.5 & 4.7 & 3.5 \\
\hline
\end{tabular}


Cuadro 3 (continuación)

\begin{tabular}{|c|c|c|c|c|c|c|}
\hline América Latina & 1964 & 1967 & 1974 & 1978 & 1984 & 1991 \\
\hline Jamaica $(1991)^{\mathbf{u}}$ & 4 & 3.7 & 3.8 & 2.4 & 2.6 & 2.2 \\
\hline Martinica & $\ldots$ & $\ldots$ & $\ldots$ & $\ldots$ & $\ldots$ & $\ldots$ \\
\hline Montserrat (1990) & 5.3 & 4.9 & 4.7 & 5.1 & 5.7 & 4.8 \\
\hline San Cristóbal y Nevis $(1992)^{\mathrm{v}}$ & 3.4 & 4 & 4.3 & 5.6 & 5.8 & 6.6 \\
\hline San Vicente y las Granadinas $(1991)^{\mathrm{w}}$ & 4.4 & 4.4 & 5.4 & 5.1 & 4.9 & 4.4 \\
\hline Santa Lucía $(1992)^{x}$ & 4.7 & 4.8 & 5.2 & 4.4 & 3.8 & 3.7 \\
\hline Suriname $(1989)^{\mathrm{y}}$ & 5.2 & 5.3 & 5.4 & 5.8 & 5.4 & 3.2 \\
\hline Trinidad y Tabago $(1992)^{\mathrm{Z}}$ & 5.3 & 5.1 & 4.5 & 4.1 & 4.8 & 3.3 \\
\hline
\end{tabular}

Fuentes: Informes de país. Organización Panamericana de la Salud (OPS)/Organización Mundial de la Salud (OMS), Las condiciones de salud en las Américas, 1969-1972, Publicación científica, $\mathrm{N}^{\circ}$ 287, 1974; Las condiciones de salud en las Américas, 1973-1976, Publicación científica, $\mathrm{N}^{\circ} 364,1978 ;$ Las condiciones de salud en las Américas, 1977-1980, Publicación científica, $\mathrm{N}^{\circ} 427,1982$ y Las condiciones de salud en las Américas, 1981-1984; vols. I y II, Publicación científica, N 500, 1986, Washington, D.C.

a Camas de todas las dependencias. (Directorio Nacional de Hospitales de Bolivia). Egresos y utilización sólo para el Ministerio de Salud y la Seguridad Social (5096 y 2591 camas, respectivamente).

${ }^{b}$ Datos sólo para el Ministerio de Salud y la Seguridad Social (26 012 y 6929 camas, respectivamente).

c Camas de todas las dependencias. Egresos y utilización sólo para el Ministerio de Salud (26 867 camas).

d Total de camas según catastro en 1980. Egresos y utilización sólo para el Subsector Oficial (75 822 camas disponibles en promedio) (Boletín del Programa Nacional de Estadísticas de Salud No 67, 1993).

¿ Camas de todas las dependencias (Anuario de Atenciones y Recursos, 1991; Anuario de Egresos Hospitalarios, 1991).

${ }^{f}$ Camas de todas las dependencias (Anuario Estadístico del Paraguay, 1991).

g Camas de todas las dependencias. Egresos y utilización sólo para camas de corta estancia del sector público.

h Camas de todas las dependencias públicas y privadas, 1989 (11 530 públicas y 403365 privadas).

i No incluye datos para dos hospitales privados.

j Camas de todas las dependencias. Utilización para el Servicio de Medicina.

$\mathrm{k}$ Camas de todas las dependencias, en el tercer nivel solamente.

' Datos para el Sistema Nacional de Salud solamente.

${ }^{\mathrm{m}}$ Camas de todas las dependencias. Egresos y utilización sólo para el sector público (301 camas).

n Datos de camas generales solamente. Egresos y utilización sólo para Aruba (301 camas).

- Camas de todos los hospitales. Egresos y utilización sólo para hospitales de corta estancia del sector público (540 camas).

p Camas de todos las dependencias. Egresos y utilización sólo para Queen Elizabeth Hospital (539 camas).

q Camas de todos los hospitales. Egresos y utilización sólo paraPrincess Margaret Hospital (195 camas).

${ }^{\mathrm{r}}$ Camas de todos los hospitales. Egresos y utilización sólo para tres hospitales generales ( 349 camas).

s Sólo informa tener 24 hospitales.

' Camas y egresos de los hospitales público y privado. Utilización sólo para hospital público (50 camas).

u Camas de todas las dependencias. Egresos y utilización y consultas sólo para hospitales del gobierno (5 078 camas).

${ }^{\vee}$ Camas de todos los hospitales. Egresos y utilización sólo para hospitales J. N. France y Pogson (174 y 38 camas, respectivamente).

w Camas de todos los hospitales. Egresos y utilización sólo para Kingston General Hospital (207 camas).

x Camas de todas las dependencias. Egresos y utilización sólo para hospitales Victoria y St. Jude (184 y 114 camas, respectivamente).

y Camas de todas las dependencias. Egresos y utlización sólo para los cuatro hospitales generales de Paramaribo (1 213 camas).

${ }^{z}$ Camas de todas las dependencias. Egresos y utilización sólo para hospitales públicos generales (1 936 camas). Datos provisionales.

tanto que en Brasil, Chile o Venezuela se halla entre 3.5 y 4.3 y en Honduras, Paraguay, México y Colombia entre 2 y 3 cada mil habitantes.

Sin duda, el grueso de la infraestructura hospitalaria disponible en la región es de carácter público (cuadro 4); sin embargo, en la mayoría de los países es la privada la que está creciendo con más rapidez. En no pocos casos, esta es la única que en realidad está creciendo, dada la profunda crisis de financiamiento que han sufrido tanto los gobiernos centrales como las instituciones de la seguridad social en los últimos diez años. ${ }^{8} \mathrm{El}$ peso relativo de la infraestructura hospitalaria privada varía notablemente de un país a

8 En el curso de los años setenta y ochenta, las camas públicas disminuyeron de 100 mil a 93 mil en Argentina, y de 14 mil a algo más de 8 mil en Uruguay (OPS, 1993). otro, siendo insignificante, por ejemplo, en Costa Rica, los países del Caribe angloparlante o Cuba, y llegando en el otro extremo a casi $75 \%$ del total de camas disponibles, en Brasil. El promedio oscila en torno al $24 \%$ en Chile, 32\% en Argentina, 20\% en Perú y 21\% de las camas totales en Venezuela. En Costa Rica, México y en menor proporción en Colombia, es el sistema de seguridad social el que controla una parte significativa de la capacidad hospitalaria disponible.

Pese a ofrecer servicios en muchos sentidos sustitutivos, el hospital privado y el hospital público exhiben modelos muy distintos de organización del trabajo médico-asistencial. En los modelos mixtos de organización sectorial tienden a consolidarse dos formas estructurales escasamente integradas en las que se proveen servicios de diferente calidad y complejidad tec- 
CUADRO 4 América Latina y el Caribe (18 países): Camas de hospital en el sector público y en el
privado, alrededor de 1990
(Porcentajes)

\begin{tabular}{|c|c|c|}
\hline País & Sector público & Sector privado \\
\hline Argentina & 68 & 32 \\
\hline Bahamas & 89 & 11 \\
\hline Barbados $\mathbf{a}$ & 98 & 2 \\
\hline Bolivia & 84 & 16 \\
\hline Brasil & 25 & 75 \\
\hline Colombia ${ }^{a}$ & 80 & 20 \\
\hline Costa Rica ${ }^{a}$ & 98 & 2 \\
\hline Cuba ${ }^{a}$ & 100 & - \\
\hline Chile & 76 & 24 \\
\hline Ecuador ${ }^{a}$ & 70.4 & 29.6 \\
\hline Guatemala & 82 & 18 \\
\hline Honduras a & 76 & 24 \\
\hline Jamaica a & 94 & 6 \\
\hline Panamáa & 87.2 & 12.8 \\
\hline Perú ${ }^{b}$ & 80.4 & 19.6 \\
\hline Rep. Dominicana & 63 & 37 \\
\hline Uruguay $\mathrm{c}$ & 72.3 & 27.7 \\
\hline Venezuela & 79.48 & 20.52 \\
\hline
\end{tabular}

Fuente: Organización Panamericana de la Salud (OPS)/ Organización Mundial de la Salud (OMS), Las condiciones de salud en las Américas 1985-1989, Washington D.C., y datos obtenidos de las tablas de los sistemas de salud en América Latina y el Caribe.

a Datos correspondientes al año 1991.

b Datos correspondientes al año 1992.

c Datos correspondientes al año 1989.

nológica. El hospital público se encarga predominantemente de las patologías crónicas, de reducida rentabilidad, en tanto que las entidades privadas actúan de preferencia en la atención de patologías agudas y usan equipos de alta complejidad tecnológica, como son los tomógrafos computarizados, las cámaras gamma y las unidades de resonancia magnética nuclear, entre otros.

Se va configurando así progresivamente un modelo dual de atención hospitalaria pública y privada, en el que los mismos profesionales médicos actúan en ambos ámbitos, pero conforme a dos lógicas de comportamiento claramente diferenciadas. En tanto que en el hospital público priman objetivos de investigación, aprendizaje y desarrollo curricular, en el ámbito privado los objetivos pecuniarios constituyen, sin duda, la mayor motivación. Ambas esferas de acción presentan también interrelaciones: no es infrecuente que un médico atienda privadamente a un paciente en el plano ambulatorio -cobrando de la seguridad social, de los seguros de prepago, o simplemente "del bolsillo" del paciente- pero que la internación y atención hospitalaria del mismo se realice en el ámbito público y de manera gratuita. En consecuencia, los subsidios desde el ámbito público al privado son en este respecto cuantiosos. Los ejemplos de Chile o Argentina son claros en este sentido.

Otra manifestación de las interconexiones entre estos modelos duales se expresa en la derivación de pacientes desde el ámbito público al privado por parte de los profesionales médicos. Ello les permite a estos últimos expandir la demanda por sus servicios en el caso de aquellos pacientes que pueden pagar a cambio de obtener una atención más oportuna, expedita y con mayores comodidades. Estas prácticas parecerían ser más frecuentes cuanto mayor sea la participación de los profesionales en la propiedad de la infraestructura hospitalaria privada, o en otros arreglos de naturaleza comercial que les permitan participar en los ingresos así generados. Los conflictos de intereses son obvios, además de que estas prácticas interfieren con las medidas de recuperación de costos y los mecanismos redistributivos que se pongan en práctica en el ámbito público.

Los mecanismos de recuperación de costos están siendo aplicados crecientemente en el ámbito público en la región, para obtener financiamiento directamente 
de los usuarios, y en algunos casos, con fines redistributivos. ${ }^{9}$ La profesión médica no ha recibido siempre con beneplácito estas iniciativas, puesto que ellas aumentan las exigencias administrativas y obligan a mejorar los sistemas de registro y control. Dado que éstos no siempre redundan en beneficios - pecuniarios o no pecuniarios- para el profesional médico, emergen desincentivos para lograr su cooperación que resultan difíciles de contrarrestar, y que en definitiva pueden obstaculizar los intentos de aplicar políticas de recuperación de costos en el ámbito público.

Las formas de pago también inciden significativamente - al igual que en el de los servicios médicos- sobre la conducta de los agentes prestadores, y asumen las modalidades ya examinadas. En el ámbito público, todavía predominan en la mayoría de los países las formas de pago a través de transferencias presupuestarias con base retrospectiva. Sin embargo, existen experiencias de transferencia parcial de recursos mediante "pagos por acción" en Chile (tanto en los establecimientos públicos como en aquéllos traspasados a las municipalidades) y en Brasil, donde se han empleado aranceles globalizados. Podría sostenerse que la incidencia de las formas de pago en estos casos no difiere esencialmente de aquélla observada en el ámbito privado, aunque los efectos son más moderados, ya que generalmente la eficiencia productiva no es un objetivo perseguido en el ámbito público, como tampoco lo es el generar excedentes.

Más complejo es el efecto de los acuerdos contractuales de pago entre entidades de financiamiento y entidades proveedoras que se establecen en el campo de la atención hospitalaria privada. Obviamente, las modalidades que se adopten tienen fuerte incidencia en el costo y la calidad de las prestaciones, el ritmo de cambio tecnológico y la propensión de los prestadores a adoptar prácticas de diferenciación de producto y a introducir tecnologías médicas de alta complejidad. Son estas últimas las que producen señales más claras de rentabilidad, lo que impulsa a consolidar un modelo asistencial crecientemente "medicalizado" y fragmentado en especialidades y subespecialidades clínicas.

\section{El mercado de medicamentos}

El mercado de medicamentos nos confronta con un escenario regional de marcadas disparidades, tanto por

\footnotetext{
9 Los fines redistributivos se logran cuando el porcentaje de las prestaciones que paga el usuario es más alto cuanto mayor sea su ingreso.
}

el lado de la oferta — producción mas importación de medicamentos - como por el lado de la demanda. Examinemos primero el tema de la demanda.

En un extremo podríamos ubicar el caso de Argentina, donde el consumo de medicamentos oscila en torno a los 80 dólares per cápita por año, tomado el consumo a precios de farmacia. Este valor se aproxima al que exhiben países como España o Portugal, y contrasta marcadamente con el de 12 a 14 dólares en Perú, México o Costa Rica y de sólo 7 dólares en Guatemala. ${ }^{10}$

En términos teóricos, la demanda de medicamentos depende de los precios y del modelo de regulación de los mismos que usa una determinada sociedad; de la regulación del ingreso per cápita; del perfil epidemiológico de la población; de los modelos de financiamiento prevalentes en esa sociedad -cuánto del gasto es cubierto por la seguridad social y cuánto por gasto directo "de bolsillo"-; de factores culturales, como la actitud de la población frente a la automedicación, y otros.

Así, respecto de una de las variables señaladas, estudios recientes llevados a cabo en el medio europeo revelan que los mecanismos de financiamiento prevalecientes en la sociedad tienen un impacto significativo en el nivel y composición de la demanda de fármacos. En algunos países de la Comunidad Europea la seguridad social financia hasta el $100 \%$ del gasto en algunos medicamentos y emplea para ello lo que se denomina una "lista positiva" de productos sobre los que acepta otorgar reembolso. En otros casos, en lugar de una lista positiva se utiliza una "lista negativa" que indica las exclusiones, ya sea por clases terapéuticas o por productos específicos. En esta materia es dable observar en los escenarios de salud del viejo continente una diversidad de situaciones (cuadro 5).

La existencia o no de precios regulados en materia de medicamentos también influye sobre la demanda. En el ámbito latinoamericano, hasta hace poco tiempo hubo control de los precios de los fármacos en gran parte de los países de la región, siendo reciente la experiencia desregulatoria en este plano de

\footnotetext{
${ }^{10}$ Dichas cifras, sin embargo, deben ser manejadas con cierto cuidado, ya que ocultan precios muy distintos entre países, aún para medicamentos similares. Una medición más realista podría alcanzarse por la vía del número de unidades físicas comercializadas anualmente. En Argentina - con un volumen físico comercializado por año cercano a los 400 millones de unidades- el consumidor promedio tiene acceso a unas 15 unidades anuales, aproximadamente. Siguiendo la misma metodología observaríamos que el consumo físico es de 7 a 9 unidades físicas anuales en Chile, Venezuela, Brasil y Colombia.
} 
Argentina y México, entre otros países. En los últimos años los precios de los medicamentos se han elevado significativamente en términos reales en los diversos países que desregularon este mercado (cuadro 6), con lo cual la incidencia de este rubro en el gasto de las familias y en los gastos globales de salud ha aumentado considerablemente. ${ }^{11}$

Las instituciones de la seguridad social han ido reaccionando frente a este fenómeno, disminuyendo los porcentajes de reembolso, reduciendo las cobertu-

CUADRO 5

Comunidad Europea: Mecanismos de financiamiento de medicamentos y porcentajes de copago

\begin{tabular}{|c|c|c|c|c|c|}
\hline & $\begin{array}{l}\text { Hay } \\
\text { lista } \\
\text { positiva de } \\
\text { medica- } \\
\text { mentos }^{\text {a }}\end{array}$ & $\begin{array}{c}\text { Hay } \\
\text { lista } \\
\text { negativa de } \\
\text { medica- } \\
\text { mentos }^{b}\end{array}$ & $\begin{array}{c}\text { Sistema de copago prevaleciente } \\
\text { en la sociedad } \\
\text { (\% del precio de farmacia) }\end{array}$ & $\begin{array}{c}\text { Proporción } \\
\text { cubierta } \\
\text { por el paciente } \\
(\%)\end{array}$ & $\begin{array}{l}\text { Se promueve } \\
\text { o no el uso } \\
\text { de } \\
\text { medicamentos } \\
\text { genéricos }\end{array}$ \\
\hline Alemania & No & Sí & Monto fijo & 25 & Fuertemente \\
\hline Dinamarca & Sí & No & $25 / 50 / 100$ & 33 & Sí \\
\hline Francia & Sí & No & $0 / 30 / 60 / 100$ & 30 & $S i^{a}$ \\
\hline Bélgica & Sí & Sí & $0 / 25 / 50 / 60$ & 35 & $S \hat{1}^{\mathfrak{a}}$ \\
\hline Grecia & Sí & No & 20 & $\ldots$ & Sí \\
\hline Irlanda & No & Sí & Varía según el tipo de paciente & $\ldots$ & Sí \\
\hline Italia & Sí & No & 30 ó 40 & 32 & $\mathrm{Si}^{\mathrm{c}}$ \\
\hline Países Bajos & No & Sí & Monto fijo & 20 & Fuertemente \\
\hline Portugal & Sí & No & $0 / 20 / 50$ & 25 & Sí \\
\hline España & Sí & Sí & 40 & 25 & Sí \\
\hline Reino Unido & No & Sí & Monto fijo & 10 & Fuertemente \\
\hline
\end{tabular}

Fuente: M.L.Burstall, Europe after 1992. Implications for pharmaceuticals, Health Affairs, Washington, D.C., otoño 1991 , p. 157.

a Medicamentos sobre los cuales se acepta hacer reembolsos.

b Medicamentos sobre los cuales no se acepta hacer reembolsos.

c Con reservas.

CUADRO 6

América Latina (algunos países): Precio promedio por unidad a de medicamento, 1988 a 1992.

(Dólares)

\begin{tabular}{|c|c|c|c|c|c|}
\hline & 1988 & 1989 & 1990 & 1991 & 1992 \\
\hline Argentina & 2.71 & 2.26 & 3.71 & 4.58 & 5.34 \\
\hline Rep. Dominicana & 2.41 & 2.87 & 2.97 & 3.79 & 4.03 \\
\hline Centroamérica & 2.98 & 3.01 & 2.82 & 3.00 & 3.26 \\
\hline Uruguay & 1.70 & 1.73 & 2.00 & 2.43 & 3.04 \\
\hline Perú & 0.96 & 1.24 & 2.21 & 2.55 & 2.89 \\
\hline Chile & 1.56 & 1.75 & 1.99 & 2.19 & 2.51 \\
\hline México & 1.39 & 1.50 & 1.62 & 1.94 & 2.41 \\
\hline Ecuador & 0.74 & 1.00 & 1.09 & 1.64 & 2.27 \\
\hline Brasil & 1.22 & 1.32 & 1.86 & 1.46 & 2.11 \\
\hline Colombia & 1.3 & 1.47 & 1.57 & 1.71 & 2.07 \\
\hline Venezuela & 0.62 & 1.01 & 1.43 & 1.63 & 1.81 \\
\hline Promedio & 1.44 & 1.51 & 1.96 & 2.14 & 2.73 \\
\hline Aumento (\%) & 9.1 & 4.9 & 29.8 & 9.2 & 27.6 \\
\hline
\end{tabular}

Fuente: IMS AG, PM Reports, Suiza, International Medical Statistics, 1993.

a Caja u otro envase equivalente.

11 En un reciente estudio sobre el mercado farmacéutico mexicano, Brodosky indica que el precio promedio al consumidor era de 0.92 dólares en 1988 y de 2.60 dólares en 1993, lo que representaba un aumento real de más del $200 \%$; idéntico fenómeno puede obser-

varse en el caso argentino, donde la expansión ha sido desde 2.50 dólares en 1984 a casi 6 dólares por unidad en 1992 (Véanse Brodosky, 1994; Katz y Burachik, 1992). 
ras que otorgan a la compra de medicamentos o estableciendo formularios terapéuticos o listados básicos de medicamentos genéricos susceptibles de reembolso, en un intento por frenar la creciente incidencia del rubro fármacos en la cuenta global de gastos en salud.

Pasando ahora al campo de la oferta de medicamentos, podemos identificar al menos tres escenarios en la región (cuadro 7). Están primeramente aquellos países como México, Argentina o Brasil, en los que se fabrica localmente casi la totalidad de los fármacos finales que se consumen y entre $10 \%$ y $40 \%$, aproximadamente, de los principios activos o materias pri- mas farmacéuticas que emplea la industria de fármacos. En segundo lugar ubicamos otro grupo de países - Chile, Colombia - en los cuales se fabrica una proporción importante de las especialidades que se venden en plaza, pero donde casi no existe aún una industria farmoquímica local productora de materias primas farmacéuticas, de modo que estas últimas se importan casi en su totalidad. Finalmente, en tercer lugar podemos ubicar a los países más chicos, o de menor desarrollo relativo, en los que una proporción muy significativa de los fármacos finales proviene directamente de la importación $y$, por lo tanto, no

CUADRO 7

América Latina (12 países): Composición de la oferta de medicamentos, alrededor de 1987

(Miles de dólares y porcentajes)

\begin{tabular}{|c|c|c|c|}
\hline \multirow[b]{2}{*}{ Países } & \multirow[b]{2}{*}{$\begin{array}{c}\text { Mercado total }{ }^{\mathrm{a}} \\
\text { (miles de dólares corrientes) }\end{array}$} & \multicolumn{2}{|c|}{$\begin{array}{l}\text { Participación }{ }^{\mathrm{b}} \\
\text { (porcentajes) }\end{array}$} \\
\hline & & $\begin{array}{l}\text { Producción local como \% } \\
\text { del mercado total }\end{array}$ & $\begin{array}{c}\text { Participación relativa de } \\
\text { los laboratorios } \\
\text { nacionales }\end{array}$ \\
\hline Argentina & 1038878 & 95.0 & 56.6 \\
\hline Brasil & 1977878 & 83.2 & 24.5 \\
\hline Colombia & 482000 & & 25.0 \\
\hline Costa Rica & 51000 & 26.0 & 20.0 \\
\hline Chile & 132000 & 51.0 & 43.0 \\
\hline El Salvador & 45000 & & $\ldots$ \\
\hline México & 1277000 & 96.7 & 24.0 \\
\hline Panamá & 58000 & 25.5 & 9.5 \\
\hline Paraguay & 75000 & 85.6 & 63.4 \\
\hline Perú & 179072 & $\ldots$ & 27.0 \\
\hline Uruguay & 102000 & $\ldots$ & 48.4 \\
\hline Venezuela & 206684 & 95.5 & 23.0 \\
\hline
\end{tabular}

Fuente: Organización Panamericana de la Salud (OPS/OMS), Informe de la Conferencia latinoamericana sobre aspectos económicos y financieros de los medicamentos escenciales, Caracas, marzo de 1992.

a A precios de salida de fábrica a los mayoristas.

b Los porcentajes se calculan sobre valores.

existe producción local de materias primas para esta industria. Estas tres situaciones obviamente plantean interrogantes muy diversas a la política pública.

En el primero de los tres casos, a las cuestiones relacionadas con la protección del consumidor - precios y calidad de los fármacos localmente comercializados - se añaden las de política industrial, ya que se debe evaluar la conveniencia de desarrollar o no una industria farmoquímica local y el apoyo que ella debería recibir hasta alcanzar un status competitivo en el ámbito internacional.

La viabilidad de desarrollar tal industria depende crucialmente tanto del marco para la propiedad industrial que un dado país decida adoptar - leyes que admitan o bloqueen la posiblidad de patentar productos farmacéuticos, que introduzcan o no un mecanismo de "licencias obligatorias" para las nuevas mo- 
léculas farmoquímicas, que admitan o no la importación del producto terminado o la materia prima activa involucrada, que especifiquen qué es lo que constituye explotación "suficiente" de la patente, etc. -como también de cuestiones inherentes a la formación de recursos humanos calificados - biólogos, farmacólogos, virólogos, y otros- que sin duda son necesarios para avanzar en el desarrollo de una industria local de principios activos. $^{12}$

Con relación a la industria de especialidades medicinales, observamos que, con excepción de países como Argentina o Chile, donde las empresas de capital nacional han llegado a controlar una fracción importante del mercado farmacéutico local, son las firmas transnacionales las que dominan ampliamente la industria de medicamentos, siendo su participación cercana al $80 \%$ del total del mercado en Brasil, México, Perú o Venezuela.

La desregulación de los precios de los medicamentos más los cambios que en la actualidad están ocurriendo en materia de reducción arancelaria, por un lado, y la patentabilidad de productos farmacéuticos, por otro, están transformando radicalmente la atmósfera del mercado de especialidades farmacéuticas en muchos de los países de la región. Esos países se han convertido nuevamente en un escenario sumamente atractivo para las firmas de capital extranjero que durante las dos últimas décadas habían perdido interés en ellos (Brodosky, 1994; Katz y Burachik, 1992).

El nuevo marco institucional y regulatorio, por el contrario, disminuye los incentivos para el desarrollo autónomo de las empresas farmacéuticas de capital nacional, las que encuentran ahora estímulo para operar como licenciatarias locales de grandes grupos transnacionales, aprovechando las ventajas de sus canales de distribución, fuertemente consolidados en los mercados de la región, y su experiencia para operar con la comunidad médica local. El modus operandi de la industria está experimentando un fuerte proceso de transformación y la vitalidad de los mayores laboratorios farmacéuticos de la región se está redefiniendo en el marco de un nuevo acuerdo de colaboración con firmas transnacionales.

Algo distinto es lo que ocurre con la producción de materias primas farmacéuticas, campo en el que

12 Es útil recordar que países como Suiza, Japón o Italia no admitieron por largos años la patentabilidad de productos farmacéuticos en defensa de su propia industria química. Sólo cuando ésta había adquirido status competitivo internacional dichos países suscribieron el Tratado de la Convención de Paris de 1883, y comenzaron a operar conforme a reglas del juego internacionales en materia de propiedad industrial ( Katz, 1972 y 1974). empresarios locales de México, Brasil y Argentina habían alcanzado hasta fechas recientes un progreso de cierta significación basado en la "copia temprana" de nuevas moléculas farmoquímicas. Esto se hacía al amparo de una ley de patentes débil que no protegía la patentabilidad de productos, de una protección arancelaria que permitía a esos empresarios fabricar principios activos en plantas de pequeña dimensión, y de un mecanismo para otorgar certificados de comercialización de nuevos medicamentos, particularmente sesgado en su favor.

El núcleo de empresas de capital nacional que consiguió establecerse en las últimas tres décadas merced al régimen regulatorio vigente parece enfrentar hoy serias dificultades de sobrevivencia. Los programas económicos de apertura y liberalización de la actividad económica y las nuevas ideas que en materia de propiedad industrial están ganando terreno en la región ante la activa presión de los países desarrollados en el marco del GATT (Reichman, 1993), hacen dudoso que los empresarios nacionales puedan continuar desarrollando esta industria a través de la copia temprana de moléculas farmoquímicas de reciente descubrimiento en países avanzados, y de su fabricación local en plantas químicas pequeñas, de tipo multipropósitos.

Los elevados costos de investigación y desarrollo involucrados en la búsqueda de nuevos principios activos; la patentabilidad de productos; la reducción de las barreras arancelarias que hasta fecha reciente hacían rentable la producción local de materias primas farmacéuticas, y finalmente, la eliminación de los privilegios que con frecuencia concedía la autoridad local de salud, otorgando a los fabricantes locales acceso prioritario a los certificados de comercialización, permiten hoy dudar del futuro de las industrias farmoquímicas locales. Así, el nuevo cuadro institucional y regulatorio prácticamente está eliminando los pilares mismos sobre los que se apoyó el desarrollo de las empresas de capital nacional en décadas pasadas y con ello modificando de manera profunda el comportamiento sectorial de largo plazo.

Habiendo examinado hasta aquí algunos de los rasgos microeconómicos que inciden en el comportamiento de los principales mercados de bienes y servicios utilizados por el sector salud, nos parece necesario pasar ahora al estudio de las interdependencias que median entre todos ellos y de la importancia que éstas tienen para el comportamiento global del sector; su eficiencia, su eficacia y el acceso equitativo a él. 


\section{Interdependencia de los mercados}

Los mercados de los bienes y servicios requeridos para el cuidado y recuperación de la salud de una población dada exhiben múltiples y complejas formas de interdependencia. Así, por ejemplo, un parto puede significar menos gastos de hospitalización si la paciente ha recibido más cuidados prenatales, los que son provistos en atención ambulatoria. $\mathrm{O}$ puede requerir más gastos de internación y de medicamentos si el profesional médico opta por realizar el parto por cesárea. Esto último puede ocurrir por razones terapéuticas; pero también puede deberse a que, por ejemplo, el profesional involucrado encuentra que este camino le permite optimizar el uso de sus horas de trabajo profesional, evitando los tiempos de espera. También puede deberse a que el arancel de prácticas médicas establece un pago más alto para un parto por cesárea que para uno vaginal de carácter convencional. Ejemplos de esta índole sin duda abundan y no es necesario extendernos en su ennumeración.

Lo anterior muestra que muchos de los bienes y servicios aquí transados son sustituibles entre sí en diversos grados; por tanto, el sistema de precios relativos se comporta en los hechos como un poderoso mecanismo de redistribución de los recursos globalmente disponibles entre los agentes prestadores. Así, por ejemplo, la relación entre el arancel médico y el arancel hospitalario, así como entre el arancel hospitalario y el precio de los medicamentos, deben verse como verdaderos canales de transferencia de ingresos entre los diversos mercados, y dentro de ellos, entre los distintos proveedores. Por eso no resulta sorprendente que estos temas sean centrales en las negocia- ciones entre los ministerios de salud pública, los sistemas de seguridad social, los colegios profesionales, las asociaciones empresariales representantes de laboratorios farmacéuticos, las entidades de prepago médico y otras.

El marco regulatorio de cada sociedad para los servicios de salud tiene sin duda que enfrentar estos aspectos de crucial importancia para el comportamiento del modelo prestador, puesto que de ello dependen principalmente la eficiencia, eficacia y equidad del sistema.

Existe otro plano en el que las interdependencias de los mercados son también notorias. Estudios recientes parecen indicar que un consumidor dado de servicios de salud no siempre se comporta exclusivamente como un paciente del sistema de seguridad social o como un paciente del sector público, sino que tiende a "combinar" sus distintas alternativas de adscripción para maximizar el conjunto de bienes y servicios que recibe del sistema de salud. (así lo señalaba Lastiri a J. Katz en carta personal sobre el tema). Por ejemplo, un operario adscrito a una Isapre chilena puede obtener atención ambulatoria financiado por esa vía, pero opta por la hospitalización en el ámbito público - sin declarar su afiliación al sistema de Isapres- a fin de lograr gratuidad en la provisión de atenciones de mayor complejidad y costo y la entrega gratuita de medicamentos. ${ }^{13}$ Esto nos muestra que también hay interdependencias y subsidios cruzados entre el ámbito publico y el privado, y que para comprender acabadamente el funcionamiento sectorial debemos integrar a ambos subsectores en una sola visión de conjunto y no tratarlos como compartimentos estancos.

\section{III}

\section{Estrategias futuras y políticas regulatorias}

\section{Políticas activas y pasivas en el campo de la salud}

Es posible identificar en la escena contemporánea dos modalidades claramente distintas de conducción de la política pública en materia de salud. Encontramos, por un lado, lo que podríamos calificar como políticas activas de modificación de la combinación público/privada de financiamiento y prestación de servicios. Y por otro, innumerables experiencias de rees- tructuración pasiva del sector, resultantes de la ausencia de políticas explícitas por parte de la autoridad de

\footnotetext{
13 Entrevistas en hospitales públicos chilenos y argentinos confirman que tanto como 20 a $25 \%$ de los pacientes atendidos en la esfera pública, con un copago nominal ínfimo, corresponde a pacientes de Isapres - en el caso de Chile-o de la Seguridad Social en Argentina; son los que simplemente optan por no declarar su afiliación a fin de obtener gratuitamente insumos o servicios no cubiertos en sus planes de salud en el ámbito privado o paraestatal, lo que sin duda involucra un importante subsidio encubierto a favor del sector privado.
} 
salud en lo que atañe a organización y comportamiento de los mercados proveedores de bienes y servicios en este sector.

En este último caso, la reestructuración y organización de dichos mercados está ocurriendo como respuesta autónoma del mercado. ${ }^{14}$ Estos fenómenos están alterando profundamente el funcionamiento del mercado de fármacos, los ritmos de migración de los profesionales médicos y otros desde el ámbito público al privado, la tasa de crecimiento, el nivel de complejidad de la infraestructura sanatorial privada, etc.

Dado que dicha reestructuración del modelo de organización sectorial ocurre en situaciones de mercados sumamente imperfectos, no debe asombrarnos que esté dando origen a numerosos problemas nuevos de eficiencia microeconómica y equidad distributiva del tipo de aquellos examinados previamente. Estos problemas tienden a presentarse aún en los países que han efectuado un proceso de reestructuración sectorial activa, como Chile (Miranda, 1993a y 1990), y con más razón aún cabe esperar que surjan allí donde el Estado adopta una conducta pasiva. Los aumentos de costos, la inequidad de acceso, la consolidación de un modelo médico excesivamente volcado a lo individual y reparatorio en lugar de lo comunitario y preventivo, la dualización del modelo de prestaciones, etc., constituyen algunos de los peligros ciertos de la reorganización sectorial pasiva, sin un adecuado programa de la autoridad de salud y de la autoridad responsable por el funcionamiento global de la economía.

Para enfrentar estas tendencias "naturales" se precisa una política de salud activa y coherente de la autoridad pública, que sea capaz de reflejar las particularidades de cada sociedad y los elementos condicionantes que emanan de su evolución histórica. La política de salud activa necesariamente deberá abordar la problemática de los diversos mercados, tal como ha sido expuesta en las páginas precedentes. A continuación se identifican algunos de los problemas centrales que en cada caso deberá enfrentar la política de salud en años venideros.

\section{La política de salud en el ámbito de los servi- cios médicos}

Tal como vimos en la sección II, apartado 1, el funcionamiento del mercado de servicios médicos está

\footnotetext{
${ }^{14} \mathrm{El}$ desarrollo de los mercados ha dado origen a lo que se conoce en la literatura reciente como nuevas formas organizacionales (véase OPS-CEPAL, 1994, pp. 39 a 51).
}

fuertemente condicionado por variables provenientes tanto del lado de la oferta como del de la demanda. En relación a la oferta, interesa particularmente examinar el impacto que sobre el funcionamiento del mercado tiene el ritmo de incorporación de nuevos profesionales y el distinto grado de saturación relativa que dicho mercado exhibe en los diversos países de la región. A su vez, el ingreso de nuevos profesionales al mercado aparece condicionado por el crecimiento de la matrícula universitaria, el grado de especialización, la localización y el sexo de los recursos humanos, y por el sistema educativo en el que se forman los profesionales de la salud.

En los hechos, el sistema educativo cumple un rol fundamental, pues determina el número de estudiantes que ingresan año a año a la formación profesional, la calidad de la educación brindada y la actitud e ideología médico-asistencial con que dichos estudiantes emergen a la vida profesional.

Por el lado de la demanda, el mercado se caracteriza cada vez más por la multiplicidad de instituciones empleadoras -las que pueden pertenecer al ámbito publico, privado, o de la seguridad social. Esta fragmentación, y la falta de coordinación de los servicios en torno a un sistema unificado de salud, consolida cada vez más un modelo dual de organización del trabajo médico-asistencial, cargado de imperfecciones y con fuertes diferencias de calidad, de eficiencia microeconómica y de equidad entre los diversos ámbitos ocupacionales.

La fragmentación y falta de coordinación entre el sector público, el privado y el ámbito de la seguridad social es uno de los temas centrales que debe encarar la política de salud. Desde esta perspectiva se reclama una clara acción programadora del sistema en su conjunto por parte de la autoridad central.

Tanto por el lado de la oferta como por el de la demanda de profesionales la política pública debería plantearse cuestiones inherentes al ritmo de incorporación, la calificación y la localización geográfica de los nuevos graduados como también a todo aquello que hace a las condiciones de inserción de dichos profesionales en los tres ámbitos laborales antes mencionados. Así, el examen de ingreso a la universidad, la naturaleza y duración de las residencias médicas y los requisitos de especialización y àcreditación profesional deberían adaptarse a las necesidades previstas de la infaestructura pública y privada de salud y de seguridad social de cada escenario nacional.

La implantación de normas regulatorias de los servicios de salud, y el establecimiento de estándares 
de calidad y de formas de pago por resultados antes que por acciones de salud, deberían contrarrestar las fuertes diferencias que se observan hoy en el modelo de prestaciones en cada una de las tres esferas mencionadas.

El desarrollo de programas de medicina familiar, así como en general el aumento de la atención primaria, podrían servir como mecanismos para racionalizar las puertas de acceso al sistema de servicios de salud, en un intento por mejorar el uso de los recursos y modificar la clara tendencia actual hacia la "medicalizacion" de los servicios y hacia la medicina reparatoria.

\section{La política de salud en el ámbito de los servi- cios hospitalarios públicos y privados}

La necesidad de contrarrestar las tendencias observadas en este campo y sus efectos nocivos, así como también la de moderar y orientar la creciente "dualización" de los servicios hospitalarios provistos en los ámbitos público y privado, apunta a la conveniencia de establecer normas para la hospitalización en servicios públicos y privados, y pautas claras para la referencia cruzada de pacientes entre instituciones públicas y privadas, con el fin de evitar la duplicación de equipos caros y el uso ineficiente de tecnologías complejas que requieren fuertes inversiones. También se hace necesario evaluar los actuales mecanismos presupuestarios para transferir el financiamiento, y las formas de pago por acción de salud frente a las de pago por resultados, como son los mecanismos de pago capitado y de aranceles globalizados o por "grupos de diagnóstico". 15

En síntesis, para crear una genuina red públicoprivada de servicios hospitalarios es necesario programar la infraestructura hospitalaria de ambos tipos, aplicando criterios de referencia cruzada de pacientes, para evitar la duplicación innecesaria de instrumental y equipos complejos, camas, etc.

La descentralización administrativa de los servicios públicos debería ser parte importante del programa de articulación de la infraestructura hospitalaria pública y privada hoy disponible. También parece necesaria la difusión de tecnologías de gestión adminis-

\footnotetext{
${ }^{15}$ Los datos relativos a Estados Unidos muestran que el cambio en las formas de pago ha tenido básicamente dos efectos: una disminución del tiempo medio de hospitalización por paciente y una baja en las tasas de admisión. Esto último se debió a un aumento en las tasas de atención ambulatoria, que Medicare continuaba pagando por acto médico (Pauly, 1987).
}

trativa que permitan optimizar el uso de esa infraestructura.

El carácter anárquico que asumió en muchos países de la región la incorporación de equipos de alto costo y gran complejidad tecnológica, sin duda reclama la implantación de mecanismos y normas a escala nacional para regular el ritmo de incorporación de tales equipos, su distribución equilibrada en los ámbitos público y privado, su adecuado mantenimiento a través del tiempo y el establecimiento de normas para su uso. Es interesante comparar el alto grado de control que en esta materia ejerce la autoridad de salud de muchos de los países desarrollados, ${ }^{16}$ con lo anárquico y costoso desde el punto de vista social que es el proceso en gran parte de los países de la región.

Están involucradas aquí cuestiones inherentes a la verdadera capacidad regulatoria del Estado latinoamericano típico, y a la medida en que puede realmente abordar esta tarea. No se trata sólo de la capacidad de regulación en este ámbito, sino de una problemática global de reingeniería institucional, legal y normativa en todo el sistema de salud. El tema afecta casi por igual a todos y cada uno de los países de la región.

\section{Las políticas de salud y la política industrial en el campo de los medicamentos}

¿Cuál es el nivel "adecuado" de consumo de fármacos que una sociedad debe alcanzar? ¿Cuánto de dicho consumo debe ser cubierto por productos de marca y cuánto por productos genéricos? ¿Qué proporción sería razonable abastecer a partir de empresas de capital nacional, o a través de empresas transnacionales? ¿A qué precios? ¿Con qué financiamiento de la seguridad social, del Estado o de los seguros privados, en contraposición a los pagos directos ("de bolsillo")?

Sin duda, estas preguntas se plantean a la autoridad de salud y económica de cada uno de nuestros países, y cada uno enfrenta la necesidad de diseñar y aplicar una política nacional de medicamentos adecuada a las peculiaridades de su situación nacional.

Hasta ahora, el lanzamiento de nuevos fármacos al mercado ha estado sujeto al requisito de que la empresa titular del medicamento probara la seguridad y eficiencia del principio activo involucrado, previa obtención de un certificado de comercialización emi-

\footnotetext{
${ }^{16}$ Respecto de siete países europeos, véase Miranda, (1993c).
} 
tido por la autoridad de salud. El actual debate en pro de la contención de los costos está haciendo que diversos gobiernos agilicen los mecanismos de aprobación de productos genéricos, y añadan a los requisitos pruebas de costo-efectividad de los nuevos principios activos que se aprueben para comercialización. Por ejemplo, Australia implantó hace poco un mecanismo con estas características, lo que sugiere que se podría explorar la conveniencia de implantar en el futuro un esquema similar en la región..$^{17}$

La expansión de la oferta de medicamentos genéricos constituye otro camino adecuado para contener costos. Con este fin se precisa una política de información dirigida a médicos, farmacéuticos y consumidores, y un marco regulatorio que autorice a los farmacéuticos a sustituir productos de marca por genéricos cuando las condiciones de precio y las características del paciente lo permitan. La legislación estadounidense de 1984 avanzó significativamente en esta dirección.

En el ámbito de la seguridad social y de las entidades de financiamiento y seguros, también son necesarios protocolos de financiamiento que den prioridad y mayor reembolso al gasto en productos genéricos. La otorgación más rapida de certificados de comercialización para este tipo de productos también constituye una acción de política pública que la autoridad de salud de diversos países desarrollados ha puesto en práctica en años recientes con relativo exito, y que sin embargo aún ha sido poco utlizada en la región ${ }^{18}$

El mercado de fármacos nos confronta, sin embargo, con varios otros temas que van más allá de los precios y calidad de los productos comercializados. Entre ellos aparecen los complejos problemas de propiedad industrial y patentes de invención, así como los que se relacionan con las ventajas comparativas dinámicas que podrían estar asociadas al desarrollo de una industria farmoquímica local de cierta envergadura. En este campo están involucrados complejos fenómenos de relaciones internacionales derivados de la afiliación de muchos de los países de la región al Tratado de la Convención de París de 1883 , y lo que ésta prevé sobre igualdad de trato a

\footnotetext{
17 Desde enero de 1993 ...”toda nueva droga presentada para aprobación debe ir acompañada no sólo de los resultados de farmacología clínica - para probar seguridad y eficacia - sino también de un estudio de su impacto económico". Ese estudio debe estar basado en comparaciones con tratamientos alternativos y debe cubrir
}

nacionales y extranjeros y sobre la protección de las patentes.

Los países enfrentan aquí diversos problemas de índole política que no resulta fácil soslayar. Uno de ellos es la innegable presión que el Departamento de Estado y la Secretaría de Comercio de los Estados Unidos han ejercido a lo largo de la última década en diversos países de la región (Argentina, Brasil, Chile y México, entre otros) y en foros internacionales como la UNCTAD o el GATT para conseguir que se modificara la legislación sobre patentes a fin de robustecerla. Ello, con el propósito de que se cumplan las normas internacionales sobre patentes en el caso de los productos farmacéuticos - $\mathrm{e}$ incluso en los propios procesos de innovación (innovative pipeline) que estén en marcha- y, de manera más general, de que se fortalezca la posición en el mercado de los laboratorios transnacionales. Estos últimos han debido enfrentar en el pasado la competencia de empresas nacionales, tanto en el mercado de productos finales como en el de materias primas farmacéuticas.

Países hoy maduros en el campo farmacéutico y farmoquímico —como Suiza, Japón o Italia- optaron en el pasado por no cumplir durante largas décadas con los reclamos sobre patentes de invención. Sólo cuando consideraron que sus empresas nacionales habían alcanzado un nivel de desarrollo suficiente para enfrentar la competencia internacional, decidieron incorporarse a los tratados internacionales en la materia (Penrose, 1951). Pero el escenario internacional contemporáneo y la situación de condicionalidad que enfrenta el financiamiento internacional de los programas macroeconómicos de ajuste de muchos de los países latinoamericanos están lejos de permitir una conducta semejante.

Pareciera ser entonces que los privilegios obtenidos en el pasado en la región por la industria farmoquímica y farmacéutica local son insosienibles en el futuro. De allí que la conveniencia de una política industrial encaminada a generar ventajas comparativas dinámicas en estas áreas amerite al menos su discusión explícita por los estamentos técnicos y políticos de cada sociedad.

no solo el precio de la droga en sí, sino también una comparación de su efecto con el de otras vías para resolver el mismo cuadro clínico, incluyendo tiempos de hospitalización y otros servicios complementarios demandados por las terapias alternativas evaluadas (Financial Times, 1994).

18 Véase el caso de los Estados Unidos en Olson, (1991a). 


\section{IV}

\section{Reflexiones finales}

En el clima global de liberalización y privatización de la actividad ecónomica vivido en la última década, parece suponerse sin gran debate que la desregulación de los mercados de salud, la introducción de patentes de producto en el campo farmacéutico y la gradual privatización del financiamiento y la provisión de los servicios de salud constituyen el desideratum de la política económica en el sector salud. Se da por sentado que el libre funcionamiento de los mercados y la libertad de elección de los consumidores habrán de traer aparejados una mayor eficiencia microeconómica, más eficacia en las prestaciones y mejor acceso a los servicios de salud.

La información empírica, sin embargo, muestra que en el campo farmacéutico la eliminación del control de los precios ha estado asociada en los ultimos años a un alza significativa de ellos. La reducción de la protección arancelaria y la introducción de nuevas reglas del juego en materia de patentes de invención, por su parte, han inducido a muchas empresas argentinas, brasileñas y mexicanas a suspender la producción local -incluso de productos previamente exportados- y a transformarse en licenciatarias de firmas transnacionales. Esto ha llevado también a abandonar esfuerzos internos tanto de investigación y desarrollo como de adaptación y mejora de procesos.

En el ámbito de los servicios médicos y hospitalarios, la desregulación de los mercados y su progresiva formalización y desarrollo han alentado la migración profesional desde el sector público al privado, con la consiguiente explosión de costos que esto trae aparejado. Asimismo, han hecho aflorar las imperfecciones que caracterizan a los mercados de salud, favoreciendo conductas que permiten a los proveedores aumentar la demanda de sus servicios, ge- nerar sobreprestación e inducir al sobreconsumo. Por otra parte, el dinamismo de la oferta ha tendido a concentrarse en la innovación tecnológica y en las áreas de mayor rentabilidad, con diferenciación de productos y discriminación de precios. El juego de estas tendencias está agudizando el dualismo del modelo de prestaciones de salud, y causando aumentos de costos y mayor inequidad.

Todos estos efectos son, sin duda, algunas de las consecuencias no deseadas y de los costos de las políticas de apertura y desregulación de la economía que, hasta el presente, han recibido escasa consideración. Dada la gran interdependencia de los distintos mercados del sector de la salud, resulta claro que estos fenómenos han estado lejos de tener un efecto neutro sobre el conjunto del sistema. Por el contrario, las presiones en cada uno de esos mercados se han difundido y han reforzado aquéllas presentes en los otros, generando un progresivo deterioro del equilibrio financiero de las instituciones de seguridad social y del Estado.

Las ideas desregulatorias y de libre juego del mercado, que parecen adecuadas en otros campos de la vida económica, no son necesariamente lo más apropiado en este ámbito de la vida comunitaria, en especial cuando los principios se aplican en forma mecánica y sin debida consideración a las peculiaridades y a los aspectos institucionales y culturales del sector salud en cada país. En este sector cargado de rasgos idiosincráticos no parece aconsejable utilizar recetas universales y de carácter convencional. De allí la necesidad de diseñar y poner en práctica un adecuado modelo regulatorio apoyado en la reingeniería institucional, legal y normativa que sea necesaria en cada caso nacional.

\section{Bibliografía}

Banco Mundial (1993): Informe sobre el desarrollo mundial 1993, Washington, D.C.

Belmartino S., C. Bloch, I. Luppi, Z. Quinteros y M.C. Troncoso (1990): Mercado de trabajo y médicos de reciente graduación. Publicación $\mathrm{N}^{\circ}$ 14, Buenos Aires, Organización Panamericana de la Salud (OPS), Representación Argentina.

Brodosky, J. (1994): La industria farmacéutica y farmoquímica mexicana en el marco regulatorio de los años 1990, México, D.F., mimeo.
Burstall, M.L. (1991): Europe after 1992. Implications for pharmaceuticals, Health Affairs, Washington, D.C., otoño.

Feldstein, P. (1983): Health Care Economics, New York, J. Wiley $\&$ Sons.

Financial Times (1994): Drug development costs, Londres, 23 de marzo.

Greenwald, L. (1991): Health care expenditure in twenty four countries. Health Affairs, vol. 10, $\mathrm{N}^{\circ} 3$, Washington, D. C., otoño.

IMS A.G. (1993): PM Reports, Suiza, International Medical Statistics. 
Katz, J. (1972): Legislación internacional de patentes, actividad inventiva local y corporaciones multinacionales, Buenos Aires, Instituto Torcuato di Tella, mimeo.

(1974): Medicamentos, empresas nacionales y corporaciones multinacionales, Buenos Aires, Editorial Siglo XXI.

Katz. J. y A. Muñoz (1988): Organización del sector salud y puja distributiva, LC/BUE/G. 102, Buenos Aires, Centro Editor para América Latina/CEPAL.

Katz, J. y G. Burachik (1992): La industria farmacéutica y farmoquímica argentina en la década de los años 1990, Buenos Aires, mimeo.

Miranda, E. (1988): Economía y salud: ¿Conflicto o cooperación? Revista administración en salud $N^{o} 4$, Santiago de Chile, Universidad de Chile, Programa Interfacultades en Administración de Salud (PIAS), septiembre.

(1990): Descentralización y privatización del sistema de salud chileno. Estudios públicos $\mathrm{N}^{\circ} 39$, Santiago de Chile, Centro de Estudios Públicos (CEP), invierno.

(1993a): Evaluación de la experiencia chilena con las ISAPRES. M. Virgolini y G. González (eds.), Tendencias económicas de los sistemas de salud, Buenos Aires, Asociación de Economía de la Salud de Argentina/ Banco Mundial.

(1993b): Sistemas de salud en el mundo. Parte I: Un marco conceptual para el análisis. Serie documentos de trabajo, $\mathrm{N}^{\circ}$ 203, Santiago de Chile, CEP, noviembre.

(1993c): Sistemas de salud en el mundo. Parte II: Casos seleccionados y sus lecciones para Chile, Serie documentos de trabajo, $N^{\circ}$ 203, Santiago de Chile, CEP, noviembre.

Olson, M. (1991a): Political Influence and the Development of U.S. Regulatory Policy: The 1984 Drug Legislation, Discussion paper series, $\mathrm{N}^{\circ} 249$, Stanford, California, Stanford University, Center for Economic Policy Research (CERP).

(1991b): The U.K. Pharmaceutical Industry and the NHS, Discussion paper series, $\mathrm{N}^{\circ} 250$, Stanford, California, Stanford University, CERP.

OMS (Organización Mundial de la Salud) (1993): Evaluation of Recent Changes in the Financing of Health Services, Ginebra, Report of a WHO Study Group.

OPS (Organización Panamericana de la Salud) (1993): Estructura y comportamiento del sector salud en Argentina, Chile y el Uruguay. Estudio de casos y modelo histórico-evolutivo de organización y comportamiento sectorial, Cuaderno técnico, $\mathrm{N}^{\circ} 36$, Washington, D.C.
OPS-CEPAL (1994): Salud, equidad y transformación productiva en América Latina y el Caribe (LC/G. 1813 (SES.25/18), Washington, D.C./Santiago de Chile, marzo.

OPS/OMS (1974): Las condiciones de salud en las Américas 1969. 1972, Publicación científica, $\mathrm{N}^{\circ} 287$, Washington, D.C.

(1978): Las condiciones de salud en las Américas 19731976, Publicación científica, $\mathrm{N}^{\circ} 364$, Washington, D.C.

(1982): Las condiciones de salud en las Américas 1977 1980, Publicación científica, $\mathrm{N}^{\circ} 427$, Washington, D.C.

(1986): Las condiciones de salud en las Américas 19811984, Publicación científica, $\mathrm{N}^{\circ} 500$, Washington, D.C.

(1991): Las condiciones de salud en las Américas 1985. 1989, Edición 1991, Washington, D.C.

(1992): Informe de la Conferencia latinoamericana sobre aspectos económicos y financieros de los medicamentos esenciales, Caracas, marzo.

(en prensa): Las condiciones de salud en las Américas 1994, Washington, D.C.

Oyarzo, C. (1992): Financiamiento del sector salud en una situación de crisis: el caso chileno. Serie Investigación I-58. Programa Post-grado de Economía, Santiago de Chile/Washington, D.C., Instituto Latinoamericano de Doctrina y Estudios Sociales (ILADES)/Georgetown University.

(1993): La mezcla público-privada: Una reforma pendiente, Santiago de Chile, mimeo.

Pauly, M.V. (1987): Hospital finance and the behaviour of the American for-profit and not-for-profit hospitals, Hospital finance under the perspective of the new Institutional Economics, Center for the Study of the new Institutional Economics, University of Saarbruecken, julio, mimeo.

Penrose, E. (1951): The Economics of the International Patent System, Baltimore, The Johns Hopkins Press.

Reichman, J. H. (1993): Implications of the Draft Trips Agreement for Developing Countries as Competitors in an Integrated World Market, Discussion papers, $\mathrm{N}^{\circ} 73$, Ginebra, Conferencia de las Naciones Unidas sobre Comercio y Desarrollo (UNCTAD).

Schieber, G.J., P.P. Poullier y L. Greenwald (1991): Health care systems in twenty-four countries. Health Affairs, Washington, D.C., otoño.

Schieber, G.J. y J.P. Poullier (1989): International health care expenditure trends: 1987, Health Affairs, Washington, D.C., otoño. 